\title{
Working conditions and tuberculosis mortality in England and Wales, 1890-1912: a retrospective analysis of routinely collected data
}

\author{
Charlotte Jackson ${ }^{1}$, Joanna H. Mostowy ${ }^{1}$, Helen R. Stagg ${ }^{1}$, Ibrahim Abubakar ${ }^{1,2,3}$, Nick Andrews ${ }^{4}$ and Tom A. Yates ${ }^{1 *}$
}

\begin{abstract}
Background: Modelling studies suggest that workplaces may be important sites of Mycobacterium tuberculosis transmission in high burden countries today. Contemporary data on tuberculosis by occupation from these settings are scarce. However, historical data on tuberculosis risk in different occupations are available and may provide insight into workplace transmission. We aimed to ascertain whether, in a high burden setting, individuals working in crowded indoor environments (exposed) had greater tuberculosis mortality than individuals employed elsewhere (unexposed).

Methods: The Registrar General's Decennial Supplements from 1890-2, 1900-2 and 1910-2 contain data on mortality from tuberculosis by occupation for men in England and Wales. In these data, the association between occupational exposure to crowded indoor environments and tuberculosis mortality was assessed using an overdispersed Poisson regression model adjusting for socioeconomic position, age and decade.

Results: There were 23,962 deaths from tuberculosis during 14.8 million person-years of follow-up among men working in exposed occupations and 28,483 during 19.9 million person-years of follow-up among men working in unexposed occupations. We were unable to categorise a large number of occupations as exposed or unexposed. The adjusted rate ratio for death from tuberculosis was 1.34 (95\% confidence interval 1.26-1.43) comparing men working in exposed occupations to those in unexposed occupations.

Conclusions: Tuberculosis mortality in England and Wales at the turn of the 20th century was associated with occupational exposure to crowded indoor environments. The association between working conditions and TB in contemporary high burden settings requires further study.
\end{abstract}

Keywords: Epidemiology, Occupation, Historical data

\section{Background}

Tuberculosis (TB) remains a major threat to human health, with an estimated 9.6 million incident cases globally in 2014 [1]. Historically, the TB burden in what today are industrialised low burden countries was higher than that currently seen in high burden countries, with mortality in some areas reaching 1000 per 100,000 per

\footnotetext{
*Correspondence: t.yates@ucl.ac.uk

The authors wish it to be known that, in their opinion, CJ and JHM should be regarded as joint first authors

${ }^{1}$ Centre for Infectious Disease Epidemiology, Research Department of Infection and Population Health, University College London, 4th Floor Mortimer Market, off Capper Street, London WC1E 6JB, UK Full list of author information is available at the end of the article
}

annum [2]. In 1901 in England and Wales, the annual risk of Mycobacterium tuberculosis (MTB) infection was estimated to have been $12 \%$ [3]. This is considerably higher than in England and Wales today and somewhat higher than risks currently observed in settings with the highest TB burden, such as South Africa [4, 5], although contemporary risks may be underestimated [6]. The reasons for the decline in TB mortality in Europe before widespread implementation of effective biomedical interventions have been extensively debated [7-11]. Mathematical modelling suggests that declines after 1900 were due to reductions in new infections rather than reductions in the rate at which people progressed from infection to disease [12]. 
In high burden settings today, molecular epidemiology suggests that, at least in adults, the majority of MTB transmission occurs outside the home [13-16]. Some occupational environments are known to carry an increased risk of TB. For example, incidence is higher in healthcare workers [17] and in miners [18] than in the general population, due to healthcare settings concentrating infectious individuals and the high risk of silicosis (which dramatically increases susceptibility to TB), respectively. However, excess risk has also been noted in Peruvian public transport workers, suggesting that occupational exposure to large numbers of contacts in indoor congregate settings may carry an independent risk [19]. Mathematical models incorporating data on ventilation and social contact patterns from a high burden informal settlement near Cape Town have also suggested that workplaces and public transport may be where most transmission of MTB between adults occurs [20].

There are few comprehensive contemporary datasets on TB burden by occupation from high burden settings. We therefore looked for historical datasets from high burden settings with which to examine the association between occupation and TB. Supplements to the Registrar General's reports from England and Wales provide causespecific mortality statistics for men for the periods 18901892 [21], 1900-1902 [22] and 1910-1912 [23], stratified by occupation and age.

By utilising these data we aimed to better understand the relationship between TB mortality and occupational exposure to crowded indoor environments before the advent of vaccines and drugs with activity against TB. Specifically, we sought to determine whether men working in indoor spaces with many other people (exposed occupations) were more likely to die from TB than men who worked mainly outdoors or had less contact with others (non-exposed occupations).

Some of the results of this study have been previously reported at a conference [24] and a symposium.

\section{Methods}

Data concerning male deaths from 'phthisis', an old name for pulmonary TB, during 1890-1892, 1900-1902 and 1910-1912 were extracted from scanned copies of the Registrar General's Decennial Supplements, available online [21-23], into a Microsoft ${ }^{\odot}$ Access 2010 database (Microsoft Corporation, Washington). These reports contain complete records of all recorded deaths in males during the respective time periods. JHM extracted numbers of deaths and person-years by age group for the 207 occupations which appeared in all three reports. A $10 \%$ random sample was checked by CJ. Discrepancies were resolved by checking the original reports. In some cases, the reports presented data separately for several subgroups of the same occupation, e.g. categorised by geographical area. We combined such subsets prior to analysis.

Before analysis, JHM and TAY independently categorised occupations as exposed or unexposed, blinded to each other's decisions (see Tables S1-S3 in Additional file 1). 'Exposure' was defined as working in an occupation likely to place workers in the same indoor public space as a substantial number of other people. This was a subjective assessment: factory work, mining, public-facing occupations and other occupations with comparable levels of exposure to crowded indoor public spaces were considered exposed. We considered enclosed public spaces, including buses and passenger trains, to be indoor public spaces. 'Unexposed' individuals worked in indoor spaces but with little contact with other people or worked outdoors. Occupations which could involve exposure to both types of environment, occupational groupings thought to contain both exposed and unexposed occupations, and occupations about which we had any doubts were placed in a third category. Discrepancies were resolved by consensus.

We adapted the socio-economic position (SEP) categorisation from the most recent of the Decennial Supplements [23], which classified occupations into eight socioeconomic groups. These are described in detail in the Registrar General's Annual Report of 1911 [25]. Three SEP categories referred to specific occupational groups (miners, agricultural labourers and textile workers); we therefore re-assigned occupations within these groups to the remaining five SEP categories with reference to a later Registrar General classification [26]. This later classification assigned all occupations to one of five socioeconomic groups, group 1 corresponding to the 'upper and middle classes', group 3 to 'skilled workmen' and group 5 to 'unskilled workmen', with groups 2 and 4 defined in the original categorisation as intermediate' between groups 1 and 3 and groups 3 and 5, respectively.

We used the age groups given in the reports for 1890-92 and 1900-02: 15-19, 20-24, 25-34, 35-44, $45-54,55-64$ and $\geq 65$ years. The dataset for $1910-12$ divided the latter age group into $65-74$ and $\geq 75$ years but, for comparability with the earlier years, we combined these into a single age group. The dataset thus comprised counts of TB deaths and denominators, split by occupation, age group and period and with the occupation-level variables SEP and occupational category.

To estimate the relative change in rate of death from TB associated with working in an exposed occupation compared to an unexposed occupation, we initially used negative binomial regression to allow for extra-Poisson variation (overdispersion) in the data [27]. However, we 
found that this generated estimates of the unadjusted rate ratio that were inconsistent with the observed data (reasons for this are discussed below). We therefore used Poisson regression, incorporating a scale parameter to account for overdispersion, to estimate crude and adjusted rate ratios comparing $\mathrm{TB}$ mortality rates between occupational groups. We adjusted a priori for the potential confounders age, SEP and report decade. The baseline group for each of these confounders was taken as that with the largest denominator. For each covariate, $\mathrm{p}$ values were derived using likelihood ratio tests to compare the given model to the null model with the scale parameter constrained to equal that estimated in the model of interest.

While investigating the reasons for the discrepant results from the negative binomial model, we noted that the association between occupational category and TB mortality appeared to vary according to the number of men employed in each occupation. We therefore also present results of post hoc analyses stratified by tertile of denominator size.

We conducted several sensitivity analyses to assess the robustness of our conclusions. First, we fitted the crude and adjusted overdispersed Poisson models to a dataset excluding occupations likely to be at elevated risk of TB mortality due to risk factors other than working indoors with many other people: healthcare professionals, farmers (who may have contact with cattle) and occupations in which workers might be exposed to dust, such as silica [22] (Additional file 1: Table S4). Second, we excluded general labourers (the occupation contributing the largest number of person-years in the uncategorised group) from the analysis. This allowed us to assess the extent to which categorisation of this large group of men, who suffered high TB mortality, determined observed differences between groups. Third, we expanded the aggregated dataset into a line listing containing the equivalent individual level data. We conducted a random effects logistic regression analysis of the resulting dataset, overall and stratified by tertile of occupation size, to take account of the potential for clustering by occupation.

All analyses were conducted using Stata 14 (Stata Corporation, Texas).

The extracted dataset and our Stata code have been made available as supplementary materials to enable readers to rerun these analyses with alternative categorisations of occupations as 'exposed' or 'unexposed' (Additional files 2-4).

This study is based on publicly available, historical, aggregated (non-identifiable) data and therefore did not require ethical approval.

\section{Results}

Where both JHM and TAY agreed that occupations were categorisable, there was agreement about exposure status in 55 of 57 instances (Cohen's Kappa 0.92). The two disagreements and all professions considered uncategorisable by either JHM or TAY were placed in the uncategorised group.

After combining subsets of the same occupation, the dataset contained information on 154 occupations. 37 occupations were categorised as exposed (occupations with extensive indoor contact), 16 as unexposed (occupations with little indoor contact) and 101 were placed in the third uncategorised group (Fig. 1 and Additional file 1: Tables S1-S3).

Amongst 646 numbers (numbers of deaths or person years of follow up time) extracted by two researchers, there were 11 discrepancies. All were found to be errors in the $10 \%$ sample entered for checking and not in the original data extract. Subsequent data exploration identified seven further errors, which were corrected, and one omitted record, which was then entered.

A total of 82.3 million person years of data were available and 164,667 TB deaths recorded (Table 1). The largest professions were coal miners (exposed, 5.9 million person-years), farm labourers or farm servants (unexposed, 5.7 million person-years) and general labourers (uncategorised, 5.7 million person-years) (Additional file 1: Tables S1-S3). Overall, the greatest number of person-years was seen in the uncategorised occupations, which also had the largest number of deaths.

Men aged 25-34 years were the largest group in all three occupational categories (Fig. 2). Crude mortality rates decreased over time in most age groups (Fig. 3b) and socio-economic categories (Fig. 3c). The highest crude TB mortality rates were among men aged 45-54 and 35-44 years. The youngest and the oldest men had the lowest mortality rates. Men with higher SEP generally had lower crude mortality rates compared to men with lower SEP, although the lowest rates occurred in SEP group 4 (which includes agricultural labourers, who had low TB mortality rates).

The crude mortality rate for $\mathrm{TB}$ was higher among men working in exposed occupations than in men working in unexposed occupations (162 versus 143 per 100,000 person-years, Table 1 and Fig. 3a). However, the highest crude mortality rates were observed in the third, uncategorised, group of occupations (235 per 100,000 person-years, Table 1). Crude mortality rates and the numbers of deaths per occupation are provided as supplementary data (Additional file 1: Tables S1-S3).

Both crude (Table 2) and adjusted (Table 3) Poisson regression models provided evidence that working in crowded indoor spaces was associated with an increase in mortality rates from $\mathrm{TB}$ compared to working indoors with little contact or in an outdoor occupation. After adjusting for age, SEP and decade, working in a crowded indoor environment was associated with a $34 \%$ higher 

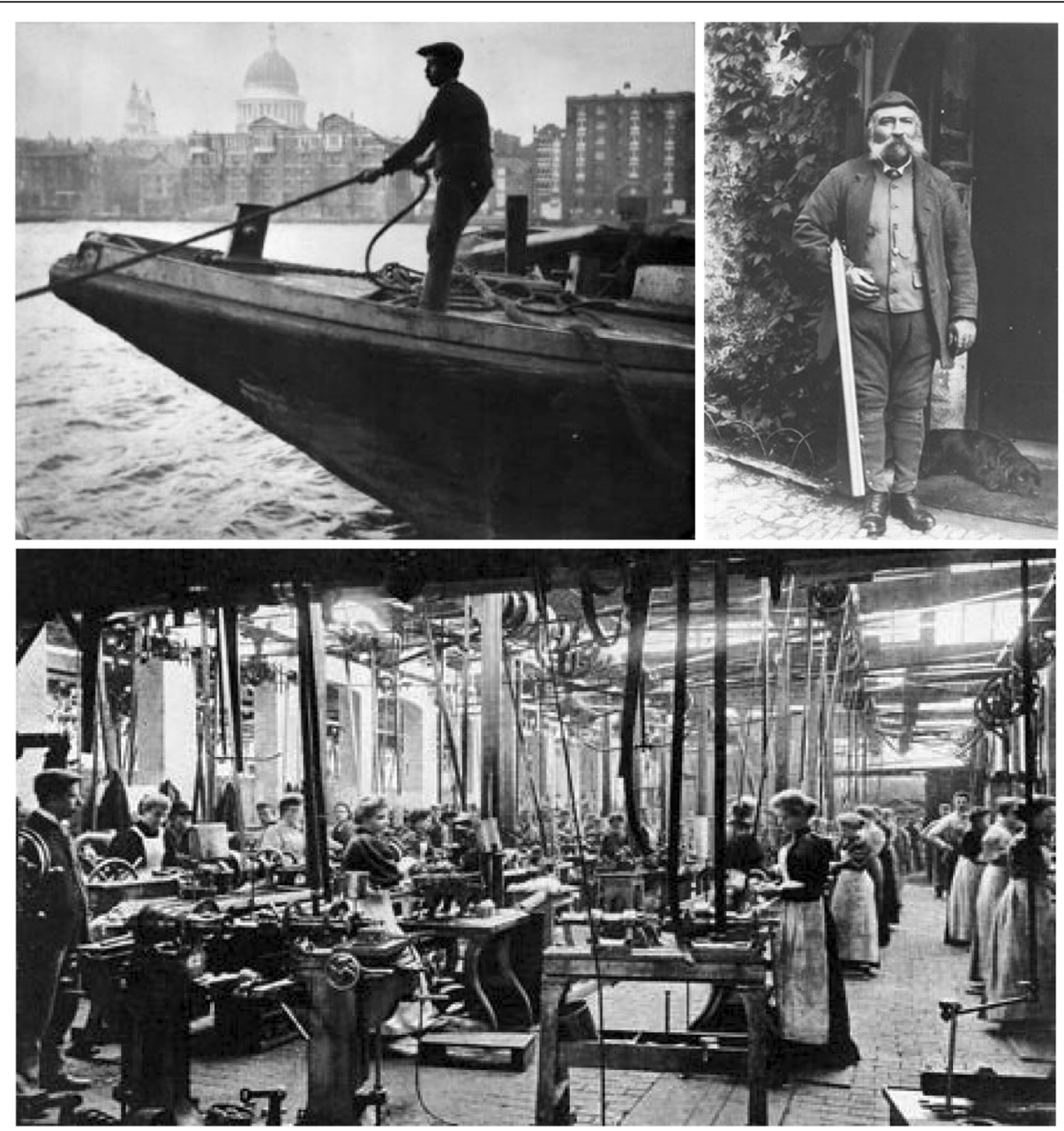

Fig 1 A London lighterman circa 1910 (top left) and, George Barnes, gamekeeper on the Dynevor estate, Wales, circa 1900 (both unexposed occupations), plus workers in a bicycle factory, Coventry, 1911 (an exposed occupation)

rate of TB mortality (rate ratio [RR] $1.34[95 \% \mathrm{CI}$ 1.26-1.43]). Men in occupations which we were unable to categorise experienced higher TB mortality rates than those whose jobs involved extensive indoor contact, with an adjusted RR of 1.71 (95\% CI 1.62-1.79) compared to men working outdoors or with little indoor contact (Table 3). Excluding the uncategorised group had little effect on the estimated crude or adjusted RR for exposed men $(1.13$ [1.02-1.25] and 1.43 [1.33-1.54], respectively [Additional file 1: Table S5]).
Sensitivity analysis excluding occupations at risk of TB for other reasons produced similar results (adjusted RR 1.46 [1.37-1.57] and 1.59 [1.51-1.68] for the exposed and uncategorised groups, respectively, compared to the unexposed (Table 3) or 1.64 [1.52-1.76] for the exposed if the uncategorised group was additionally excluded [Additional file 1: Table S6]). Excluding general labourers, the largest group of uncategorised workers, did not substantially alter estimates from the overdispersed Poisson model (adjusted RR 1.30 (95 \% CI 1.23-1.39) and 1.62 (95 \% CI 1.54-1.70)

Table 1 Total numbers of deaths from 'phthisis' and denominators by occupational category, 1890-92, 1900-02 and 1910-12

\begin{tabular}{|c|c|c|c|c|c|c|c|c|c|}
\hline \multirow[t]{2}{*}{ Period } & \multicolumn{3}{|c|}{ Exposed Occupations } & \multicolumn{3}{|c|}{ Unexposed Occupations } & \multicolumn{3}{|c|}{ Uncategorised Occupations } \\
\hline & $\begin{array}{l}\text { Number } \\
\text { of deaths }\end{array}$ & $\begin{array}{l}\text { Person years } \\
\text { of follow up }\end{array}$ & $\begin{array}{l}\text { Mortality rate per } \\
100,000 \text { per year }\end{array}$ & $\begin{array}{l}\text { Number } \\
\text { of deaths }\end{array}$ & $\begin{array}{l}\text { Person years } \\
\text { of follow up }\end{array}$ & $\begin{array}{l}\text { Mortality rate per } \\
100,000 \text { per year }\end{array}$ & $\begin{array}{l}\text { Number } \\
\text { of deaths }\end{array}$ & $\begin{array}{l}\text { Person years } \\
\text { of follow up }\end{array}$ & $\begin{array}{l}\text { Mortality rate per } \\
100,000 \text { per year }\end{array}$ \\
\hline 1890-1892 & 8003 & $3,778,203$ & 211.8 & 11,921 & $6,612,453$ & 180.3 & 35,883 & $12,692,445$ & 282.7 \\
\hline 1900-1902 & 6773 & $4,215,931$ & 160.7 & 9484 & $6,968,242$ & 136.1 & 36,543 & $15,457,624$ & 236.4 \\
\hline 1910-1912 & 9186 & $6,804,315$ & 135.0 & 7078 & $6,278,787$ & 112.7 & 39,796 & $19,541,255$ & 203.7 \\
\hline Total & 23,962 & $14,798,449$ & 161.9 & 28,483 & $19,859,482$ & 143.4 & 112,222 & $47,691,324$ & 235.3 \\
\hline
\end{tabular}




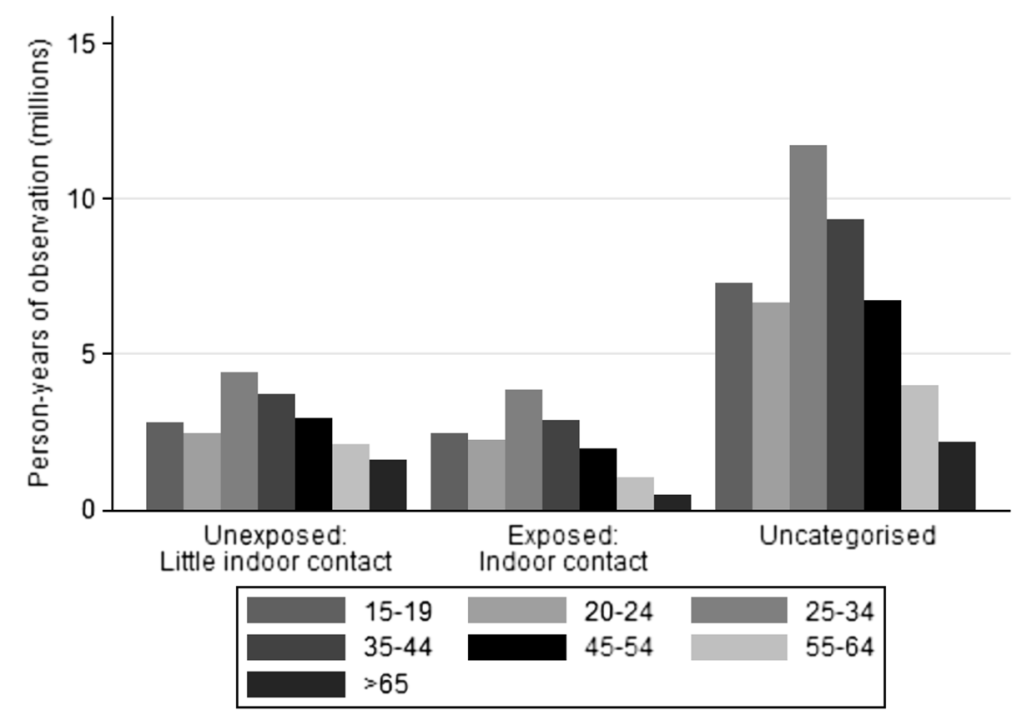

Fig 2 Person-years of observation (in millions) amongst men in each occupational category, by age group

for exposed and uncategorised occupations, respectively, Additional file 1: Table S7).

Following post hoc stratification by tertile of population size, we found that the crude (but not the adjusted) RR comparing the exposed and unexposed groups, as estimated by overdispersed Poisson regression, decreased with increasing denominator (Additional file 1: Table S8). However, when high-risk occupations (as defined a priori) were excluded and tertiles re-calculated accordingly, this trend was less evident (Additional file 1: Table S9).

The adjusted odds ratios from random effects logistic regression of the individual level dataset were 1.69 (95\% CI 1.33-2.14) for the exposed group and 1.71 (95\% CI 1.39-2.11) for the uncategorised group (Additional file 1: Table S10). When stratified by tertile of denominator (Additional file 1: Table S10), neither crude nor adjusted odds ratio estimates from random effects logistic regression differed systematically from the RRs based on the original aggregated data (Additional file 1: Table S8).

As noted above, crude results from negative binomial regression were inconsistent with the raw data. Crude and adjusted estimates from negative binomial regression, including stratification by denominator size, are presented in the supplementary material (Additional file 1: Tables S11 and S12). These estimates were similar to those from the random effects logistic regression, but with narrower CIs.

\section{Discussion}

We present evidence that working in a crowded indoor space was associated with a one-third increase in mortality rates from $\mathrm{TB}$ compared to working in other indoor spaces or working outdoors in an analysis adjusted for age, socioeconomic position and time period. TB was a leading cause of premature mortality in England and
Wales over this period, as it is currently in high burden settings [1, 2]. The force of infection in England and Wales over this period was probably higher than anywhere today, except perhaps in some modern high burden urban communities [3-6]. Levels of poverty, inequality and overcrowding may be comparable, although the climate and social context are clearly very different. Other major differences include the HIV epidemic, mass BCG vaccination and the availability of effective TB treatment, plus plausibly differences in circulating MTB strains and host genetics.

The strengths of this analysis include the size of the dataset, its (theoretical) completeness in recording cause-specific mortality for all men during these periods and the detailed categorisation of occupation. However, the study has several limitations. TB during this period was generally diagnosed clinically rather than microbiologically or using $\mathrm{x}$-ray and thus there may have been some misattribution of cause of death [28]. There may also have been a reluctance among clinicians and coroners to list TB as the cause of death, as TB was stigmatised and the diagnosis might prevent surviving family members accessing medical insurance [28]. Any such misclassification would likely be independent of working conditions and thus would bias our effect estimates towards the null. Mandatory notification of clinical TB cases was not introduced until 1912 [29] so would have very little impact on our analyses.

We used an old system to classify SEP. Whilst more detailed methods have since been developed to quantify the complex concept of SEP, modern classifications [30] would not necessarily be easily applicable to historical occupations. However, there may be some misclassification of SEP in our analysis, e.g. some occupation titles 

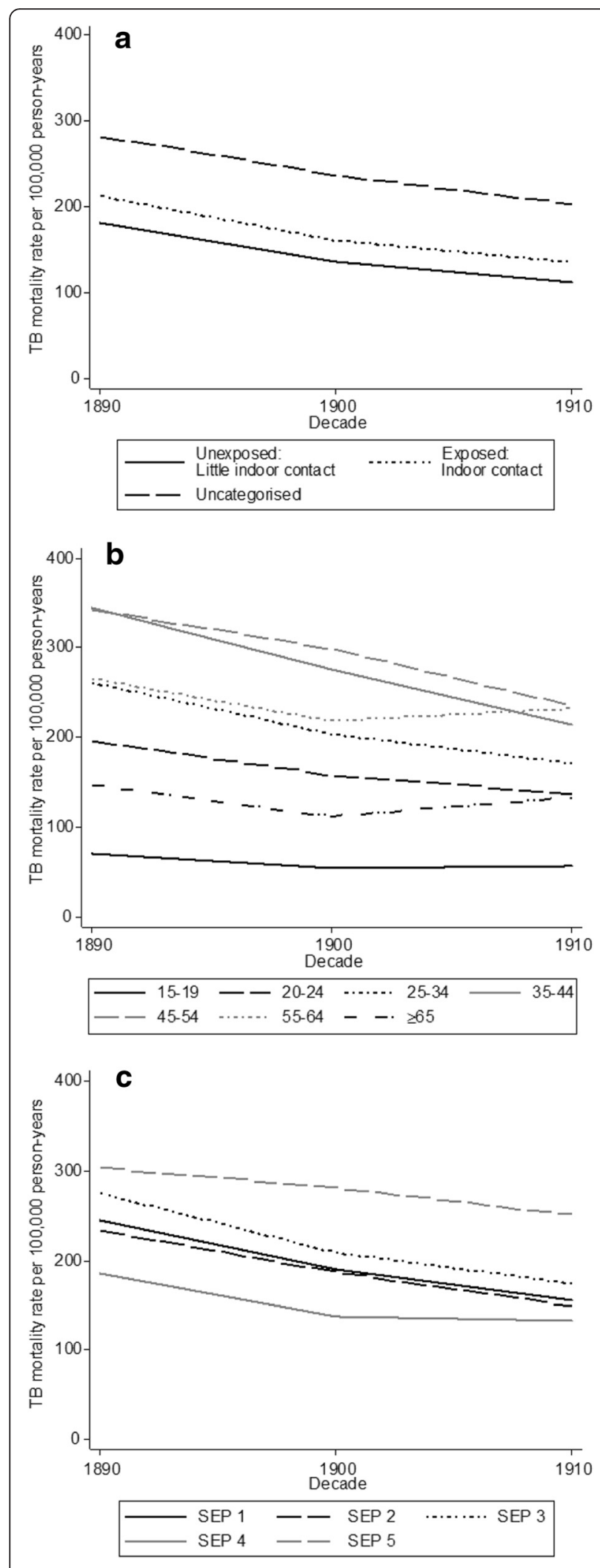

Fig 3 TB mortality rates over time (per 100,000 person-years), 1890-1912, by $\mathbf{a}$ occupational exposure to crowded indoor spaces $\mathbf{b}$ age group (in years) and c socioeconomic position (SEP, where group 1 is the highest position and group 5 the lowest)

used in the dataset did not match exactly with those used in the SEP classification, and some occupational groups might include both skilled and less skilled workers which would be combined in the same SEP category.

At the turn of the twentieth century, only $32 \%$ of females over the age of 10 years worked outside the home [31], largely women from low income households [32]. Of these, $44 \%$ worked in 'family, institutional or personal service' and $56 \%$ in industry (mostly in the clothing or textile industries) [31]. The data available to us were limited to males and thus may not be generalisable to females. However, it seems unlikely that any association between TB mortality and working in crowded indoor environments would differ substantially by gender.

Registered occupation was the last profession of the deceased men and we assumed that this was a valid proxy for exposure status at the time of acquisition of TB infection. However, men may have died from TB acquired whilst working in a different profession. It is possible, for example, that men might move into nonmanual occupations on becoming symptomatic. The direction of this bias and thus its impact on the effect estimate would depend on whether such individuals were more likely to move into or out of exposed occupations. In the source data, numbers of deaths were taken from death registers while denominators were based on census returns [22], which has at least two implications for the analysis. First, men may have changed their jobs between the census and their death, leading to inaccurate denominators. Second, there may be discrepancies between the two data sources in reporting an individual's occupation, meaning that numerators and/or denominators are incorrect [23].

The dataset contained no information on proximal risk factors for TB mortality, such as smoking, alcohol consumption, nutritional status, or comorbidities, nor did it contain data on exposure to TB in other settings, such as social venues or crowded accommodation. Whilst adjustment for SEP may have accounted for some of these differences, we cannot exclude the possibility that our results are influenced by confounding by such unmeasured factors. Specifically, we did not have data to adjust for urban versus rural residence. It seems likely that employment in exposed occupations was associated with urban residence. Should urban men have greater contact with TB outside work, smoke or drink more, be less well nourished, or be generally less healthy, this might, in part, explain the association we observed. Conceiving 
Table 2 Crude associations of occupation category and key covariates with mortality from 'phthisis'

\begin{tabular}{|c|c|c|c|}
\hline Variable & & $\begin{array}{l}\text { Crude Rate Ratio } \\
(95 \% \mathrm{Cl})\end{array}$ & $p$ value \\
\hline \multirow[t]{3}{*}{ Occupation Category } & Unexposed & Referent & $<0.0001$ \\
\hline & Exposed & $1.13(1.03-1.24)$ & \\
\hline & Uncategorised & $1.64(1.53-1.76)$ & \\
\hline \multirow[t]{7}{*}{ Age in years } & $15-19$ & $0.29(0.26-0.32)$ & $<0.0001$ \\
\hline & $20-24$ & $0.78(0.72-0.84)$ & \\
\hline & $25-34$ & Referent & \\
\hline & $35-44$ & $1.30(1.23-1.38)$ & \\
\hline & $45-54$ & $1.38(1.29-1.47)$ & \\
\hline & $55-64$ & $1.15(1.06-1.24)$ & \\
\hline & $>65$ & $0.63(0.56-0.72)$ & \\
\hline \multirow[t]{5}{*}{ Socioeconomic position } & 1 (highest) & $1.25(1.12-1.39)$ & $<0.0001$ \\
\hline & 2 & $1.24(1.14-1.36)$ & \\
\hline & 3 & $1.42(1.32-1.53)$ & \\
\hline & 4 & Referent & \\
\hline & 5 (lowest) & $1.83(1.71-1.97)$ & \\
\hline \multirow[t]{3}{*}{ Period } & 1890-1892 & Referent & $<0.0001$ \\
\hline & 1900-1902 & $0.82(0.77-0.88)$ & \\
\hline & 1910-1912 & $0.71(0.67-0.76)$ & \\
\hline
\end{tabular}

similar systematic differences as putative explanations for the high mortality in the uncategorised group is more challenging, given that this group contained such a heterogeneous set of occupations.

Although occupations were categorised independently by two researchers, the groupings made may be subject to misclassification. The large number of occupations that remained unclassified reflects the cautious approach adopted. Should occupations in the uncategorised group with high TB mortality have, truly, been unexposed then the effect would be more modest than estimated. However, the association was still observed when general labourers, the largest group of uncategorised workers, were excluded from the analysis, and when occupations at risk of TB for other reasons were dropped.

The inconsistency of the estimates from the negative binomial model with the observed data is interesting. Differences between negative binomial and quasi-Poisson models have also occasionally been noted in ecology, being attributed to the different weighting of data points in the two models: the negative binomial gives a similar weight to all observations with expected death counts above one whereas the quasi-Poisson model gives increasing weight to points with higher expected death counts [33]. The larger effect size seen with the negative binomial model can therefore be explained by the presence of some small but high risk exposed occupations, such as tin miners, lead miners and copper miners, which have greater influence on this model. This effect could also be seen when the quasi-Poisson model was fitted to data stratified by the population size where a greater effect was seen in those occupations with smaller denominators than those with larger denominators.

However, regardless of the model used and in all sensitivity analyses, we found evidence that working indoors in a high-contact environment was associated with an increased risk of dying from pulmonary TB.

\section{Conclusions}

Our finding that occupational exposure to crowded indoor environments in England and Wales at the turn of the 20th Century was associated with TB mortality should prompt urgent assessment of whether similar associations can be observed in high burden settings today. Employment in certain occupations clearly predicts TB risk $[17,18]$. A major contribution of exposure in the workplace to TB transmission, beyond specific high-risk occupations, is predicted by mathematical models [20]. Were this to be demonstrated empirically, infection control precautions, including low cost environmental modifications, might be deployed in these spaces to cut TB transmission risk [34-37] and case finding might be targeted at such workplaces [37].

\section{Ethics approval and consent to participate}

As this was an analysis of publically available, aggregated and anonymised data, we did not seek ethics approval before undertaking these analyses.

\section{Availability of data and materials}

This article has an online data supplement, containing additional tables. We have also made available the full dataset and Stata .do files for the analyses undertaken.

Table 3 Adjusted associations between occupation category and mortality from 'phthisis'. In sensitivity analysis, occupations at risk of TB for other reasons were excluded ${ }^{a}$

\begin{tabular}{llllll}
\hline & \multicolumn{2}{l}{ Including all occupations } & & \multicolumn{2}{l}{ Excluding occupations at risk of TB for other reasons } \\
\cline { 2 - 3 } Occupation category & Adjusted rate ratio $(95 \% \mathrm{Cl})^{\mathrm{b}}$ & $\mathrm{p}$-value & & Adjusted rate ratio $(95 \% \mathrm{Cl})^{\mathrm{b}}$ & $\mathrm{p}$-value \\
\hline Unexposed & Referent & $<0.0001$ & & Referent & $1.46(1.37-1.57)$ \\
Exposed & $1.34(1.26-1.43)$ & & $1.59(1.51-1.68)$ \\
Uncategorised & $1.71(1.62-1.79)$ & & \\
\hline
\end{tabular}

a Healthcare workers, farmers and occupations with dust exposure

${ }^{\mathrm{b}}$ Analysis adjusted for age, socioeconomic position and decade 


\section{Additional files}

Additional file 1: Occupations and TB mortality Supplement. (DOCX $60 \mathrm{~kb}$ )

Additional file 2: E\&W historical TB mortality data. (CSV $191 \mathrm{~kb}$ )

Additional file 3: Main analysis do file. (DOC $31 \mathrm{~kb}$ )

Additional file 4: Random effects analysis overall and by tertile of denominator. (DOC $3 \mathrm{~kb}$ )

\section{Abbreviations}

BCG: Bacillus Calmette-Guérin vaccine; HIV: Human Immunodeficiency Virus; MTB: Mycobacterium tuberculosis; RR: rate ratio; SEP: socio-economic position; TB: Tuberculosis.

\section{Competing interests}

All authors declare no conflicts of interest relevant to this manuscript. CJ and HRS have undertaken paid consultancy work for Otsuka Pharmaceutical. HRS has received money for travel and subsistence from Otsuka Pharmaceutical. TAY has worked on studies that received support from GSK and Pasante but did not benefit financially from these arrangements. HRS, IA and TAY are involved in a study that uses medicine donated by Sanofi.

\section{Authors' contributions}

TAY conceived the analysis. JHM extracted the data, with checks from CJ. $J H M, C J, H R S, T A Y$ and NJA analysed the data. JHM drafted the manuscript. CJ, JHM, HRS, IA, NA and TAY all commented on and edited the manuscript. All authors read and approved the final manuscript.

\section{Acknowledgments}

We are grateful to Dr Eilidh Garrett, a historical demographer affiliated to the Cambridge Group for the History of Population and Social Structure, for her help and advice, and to Dr Adrian Root at the London School of Hygiene and Tropical Medicine for assistance with running the random effects analysis.

\section{Sources of support}

This report is independent research supported by the National Institute for Health Research (Post Doctoral Fellowship, HRS, PDF-2014-07-008). CJ is funded by the National Institute for Health Research (NIHR). IA is funded by NIHR, Medical Research Council (MRC) and Public Health England. TAY receives a studentship from the MRC. The views expressed in this publication are those of the authors and not necessarily those of the NHS, the National Institute for Health Research or the Department of Health. The funders had no role in the analysis or interpretation of data, writing the manuscript or the decision to submit the manuscript for publication.

\section{Author details}

${ }^{1}$ Centre for Infectious Disease Epidemiology, Research Department of Infection and Population Health, University College London, 4th Floor Mortimer Market, off Capper Street, London WC1E 6JB, UK. ${ }^{2}$ MRC Clinical Trials Unit at University College London, Aviation House, 125 Kingsway, London WC2B 6NH, UK. ${ }^{3}$ Tuberculosis Section, Public Health England, 61 Colindale Ave, London NW9 5EQ, UK. ${ }^{4}$ Statistics, Modelling and Economics Department, Public Health England, 61 Colindale Ave, London NW9 5EQ, UK.

\section{Received: 14 January 2016 Accepted: 13 April 2016} Published online: 20 May 2016

\section{References}

1. World Health Organization. Global tuberculosis report 2015. Geneva: World Health Organization; 2015.

2. Rieder H. Epidemiologic Basis of Tuberculosis Control. 1st ed. Paris: International Union Against Tuberculosis and Lung Disease; 1999.

3. Vynnycky E, Fine PEM. The annual risk of infection with Mycobacterium tuberculosis in England and Wales since 1901. Int J Tuberc Lung Dis. 1997:1(5):389-96.

4. Wood R, Lawn SD, Johnstone-Robertson S, Bekker L. Tuberculosis control has failed in South Africa - time to reappraise strategy. S Afr Med J. 2011;101(2):2009-12.
5. Kritzinger FE, den Boon S, Verver S, Enarson D, Lombard CJ, Borgdorff MW, et al. No decrease in annual risk of tuberculosis infection in endemic area in Cape Town, South Africa. Trop Med Int Health. 2009;14(2):136-42.

6. Andrews JR, Hatherill M, Mahomed H, Hanekom WA, Campo M, Hawn TR, et al. The dynamics of QuantiFERON ${ }^{\circledR}$-TB Gold In-Tube conversion and reversion in a cohort of South African adolescents. Am J Respir Crit Care Med. 2015;191(5):584-91.

7. Lönnroth K, Jaramillo E, Williams BG, Dye C, Raviglione M. Drivers of tuberculosis epidemics: the role of risk factors and social determinants. Soc Sci Med. 2009;68(12):2240-6.

8. Fairchild AL, Oppenheimer GM. Public Health Nihilism vs Pragmatism: History, Politics, and the Control of Tuberculosis. Am J Public Health. 1998;88(7):1105-17

9. Newsholme A. An Inquiry into the Principal Causes of the Reduction in the Death-Rate from Phthisis during the last forty years, with special reference to the Segregation of Phthisical Patients in General Institutions. J Hyg Camb. 1906;6:304-84.

10. McKeown T. Medical issues in historical demography (First appeared in: Edwin Clarke (ed.). Modern Methods in the History of Medicine. London: Athlone Press, 1971, pp. 57-74.). Int J Epidemiol. 2005;34(3):515-20.

11. Wilson LG. The historical decline of tuberculosis in Europe and America: its causes and significance. J Hist Med Allied Sci. 1990;45(3):366-96.

12. Vynnycky E, Fine PEM. Interpreting the decline in tuberculosis: the role of secular trends in effective contact. Int J Epidemiol. 1999;28:327-34.

13. Verver S, Warren RM, Munch Z, Richardson M, van der Spuy GD, Borgdorff MW, et al. Proportion of tuberculosis transmission that takes place in households in a high-incidence area. Lancet. 2004;363(9404):212-4.

14. Buu TN, van Soolingen D, Huyen MNT, Lan NNT, Quy HT, Tiemersma EW, et al. Tuberculosis acquired outside of households, rural Vietnam. Emerg Infect Dis. 2010;16(9):1466-8

15. Middelkoop K, Mathema B, Myer L, Shashkina E, Whitelaw A, Kaplan G, et al. Transmission of Tuberculosis in a South African Community With a High Prevalence of HIV Infection. J Infect Dis. 2015;211(1):53-61.

16. Glynn JR, Guerra-Assunção JA, Houben RMGJ, Sichali L, Mzembe T, Mwaungulu LK, et al. Whole Genome Sequencing Shows a Low Proportion of Tuberculosis Disease Is Attributable to Known Close Contacts in Rural Malawi. PLoS One. 2015;10(7), e0132840.

17. Baussano I, Nunn P, Williams B, Pivetta E, Bugiani M, Scano F. Tuberculosis among health care workers. Emerg Infect Dis. 2011;17(3):488-94.

18. Corbett EL, Churchyard GJ, Clayton TC, Williams BG, Mulder D, Hayes RJ, et al. HIV infection and silicosis: the impact of two potent risk factors on the incidence of mycobacterial disease in South African miners. AIDS. 2000;14(17):2759-68.

19. Horna-Campos OJ, Bedoya-Lama A, Romero-Sandoval NC, Martin-Mateo M. Risk of tuberculosis in public transport sector workers, Lima. Peru Int J Tuberc Lung Dis. 2010;14(September 2009):714-9.

20. Andrews JR, Morrow C, Walensky RP, Wood R. Integrating Social Contact and Environmental Data in Evaluating Tuberculosis Transmission in a South African Township. J Infect Dis. 2014;210(4):597-603.

21. Supplement to registrar-general's Fifty-fifth Annual Report. London: His Majesty's Stationary Office; BPP. 1897;Pt. II (Pt.II BPP 1897 XXI [C.8503] i). Available from http://www.histpop.org. Accessed 15 Apr 2016.

22. Decennial supplement to registrar-general's Sixty-fifth Annual Report [Part II]. London: His Majesty's Stationary Office; BPP. 1908;(BPP 1905 XVIII [Cd. $2619]$ i). Available from http://www.histpop.org.. Accessed 15 Apr 2016.

23. Supplement to registrar-general's Seventy-fifth Annual Report. Part IV. Mortality of men in certain occupations in the three years, 1910, 1911 and 1912. London: His Majesty's Stationary Office; BPP. 1923. Available from http://www.histpop.org.. Accessed 15 Apr 2016.

24. Wolny J, Jackson C, Stagg H, Abubakar I, Yates T. PC-758-04 Occupational exposure to indoor congregate settings and tuberculosis mortality. Int J Tuberc Lung Dis. 2015;19(12 suppl 2):S175-6.

25. Registrar General. Seventy-fourth annual report of the registrar-general. London: His Majesty's Stationary Office; 1911. Available from http://www. histpop.org.. Accessed 15 Apr 2016.

26. Registrar General. Registrar General's Decennial Supplement, England and Wales, 1921. Part II: Occupational mortality, fertility and infant mortality. London: His Majesty's Stationary Office; 1927. Available from http://www. histpop.org.. Accessed 15 Apr 2016.

27. Hilbe JM. Negative Binomial Regression. 2nd ed. Cambridge: Cambridge University Press; 2011. 570 p.

28. Bryder L. "Not always one and the same thing": the registration of tuberculosis deaths in Britain, 1900-1950. Soc Hist Med. 1996;9(2):253-65. 
29. McCormick A. The notification of infectious diseases in England and Wales. Commun Dis Rep CDR Rev. 1993;3(2):R19-25.

30. Galobardes B, Lynch J, Smith GD. Measuring socioeconomic position in health research. Br Med Bull. 2007:81-82(1):21-37.

31. Richards E. Women in the British Economy since about 1700: an interpretation. History. 1974;59(1962):337-57.

32. McCloskey D. Paid work. In: Zweiniger-Bargielowska I, editor. Women in Twentieth-Century Britain: Economic, Social and Cultural Change. London: Longman/Pearson Education; 2001.

33. VerHoef JM, Boveng PL. Quasi-Poisson Vs. Negative Binomial Regression: How Should We Model Overdispersed Count Data? Ecology. 2007;88(11):2766-72.

34. Escombe AR, Moore DAJ, Gilman RH, Navincopa M, Ticona E, Sheen P, et al. Upper-Room Ultraviolet Light and Negative Air lonization to Prevent Tuberculosis Transmission. PLoS Med. 2009;6(3), e1000043.

35. Escombe AR, Oeser CC, Gilman RH, Navincopa M, Ticona E, Pan W, et al. Natural ventilation for the prevention of airborne contagion. PLoS Med. 2007:4(2), e68.

36. Cox H, Escombe R, Mcdermid C, Mtshemla Y, Spelman T, Azevedo V, et al. Wind-Driven Roof Turbines: A Novel Way to Improve Ventilation for TB Infection Control in Health Facilities. PLoS One. 2012;7(1), e29589.

37. Yates TA, Tanser F, Abubakar I. Plan Beta for Tuberculosis: it's time to think seriously about poorly ventilated congregate settings. Int J Tuberc Lung Dis. 2016;20(1):5-10.

\section{Submit your next manuscript to BioMed Central and we will help you at every step:}

- We accept pre-submission inquiries

- Our selector tool helps you to find the most relevant journal

- We provide round the clock customer support

- Convenient online submission

- Thorough peer review

- Inclusion in PubMed and all major indexing services

- Maximum visibility for your research

Submit your manuscript at www.biomedcentral.com/submit 